\title{
Study on the chemical composition and antioxidant activity of extracts from shoot culture and regenerated plants of Scutellaria altissima $\mathbf{L}$.
}

\author{
Izabela Grzegorczyk-Karolak • Lukasz Kuźma • \\ Halina Wysokińska
}

Received: 9 September 2014/Revised: 15 October 2014/ Accepted: 23 November 2014/Published online: 30 November 2014 (C) The Author(s) 2014. This article is published with open access at Springerlink.com

\begin{abstract}
The flavonoid (baicalin, wogonoside, luteolin, luteolin-7-glucoside) and verbascoside contents of Scutellaria altissima in both shoot cultures, and the shoots and roots of micropropagated plants grown in the greenhouse for 12 weeks or in the field for 2 years were determined. The level of secondary metabolites was found to be strongly affected by the age and type of plant organ. A comparative analysis of $S$. altissima plants propagated in vitro and from seeds revealed no differences in the level of secondary metabolites when plants of the same age were studied. The antioxidant potential of methanolic extracts from shoot cultures, and the shoots and roots of S. altissima plants propagated in vitro, were evaluated using ABTS radical scavenging, FRAP metal reduction power and the lipid peroxidation test, in relation to the content of baicalin, wogonoside, verbascoside, total phenolic and total flavonoid compounds. Extracts from the roots of field-grown regenerated plants at the flowering stage were found to possess the strongest antioxidant activity. Correlation analysis revealed that the antioxidant activity of extracts correlated most closely with their total phenolic content estimated by the Folin-Ciocalteu method.
\end{abstract}

Keywords Antioxidant activity - Scutellaria altissima . Secondary metabolite contents $\cdot$ Shoot culture

Communicated by A. Krolicka.

I. Grzegorczyk-Karolak (凶) · Ł. Kuźma · H. Wysokińska Department of Biology and Pharmaceutical Botany, Medical University of Łódź, ul. Muszyńskiego 1, 90-151 Lodz, Poland e-mail: izabela.grzegorczyk@umed.lodz.pl

\section{Introduction}

Scutellaria species belonging to the family Lamiaceae are known for the accumulation of characteristic flavones, such as baicalein, baicalin, wogonin, wogonoside, oroxylin and oroxyloside, which possess interesting medical properties (Gao et al. 1999). For example, baicalin, a flavone glycoside, which inhibits HIV-1 infection (Kitamura et al. 1998), has proven anti-allergic properties and is known to have a scavenging effect in protecting the membrane of erythrocytes from free radical injuries (Gao et al. 1999). Chang et al. (2002) report that baicalin inhibits the proliferation of various human hepatoma cell lines. Wogonoside has strong activity against lipid peroxidation and an inhibitory effect on histamine and IgE production (Lim 2003). The compound can inhibit lipopolysaccharide-induced angiogenesis (Chen et al. 2009). Another important group of phenolic compounds detected in Scutellaria plants is composed of phenylethanoid glycosides such as verbascoside and martynoside (Shang et al. 2010). Verbascoside, which earlier was found in organogenic calli of S. altissima (Grzegorczyk-Karolak et al. 2013), has shown anti-inflammatory, antibacterial, antioxidant and antitumor activity (Pan et al. 2003).

One of the most popular species in the Scutellaria genus is $S$. baicalensis, which has been used in traditional Chinese and Japanese medicine. Few data about the quantitative production of bioactive compounds in other than $S$. baicalensis species are available (Wiczanska-Barska et al. 2012; Islam et al. 2011; Cole et al. 2008; Zgórka 2006). To search for natural medicine sources, it seems worthwhile to define the profile and content of secondary metabolites in other members of the Scutellaria genus. As the object of the present study, we have chosen S. altissima plant. This species grows in the woody regions of Southern Europe 
and North America and is known for the accumulation of valuable compounds similar to those occurring in $S$. baicalensis (Beshko et al. 1975). Previously, it was found that the organogenic calli of $S$. altissima produced high contents of polyphenolic compounds, especially baicalin (Grzegorczyk-Karolak et al. 2013).

Plant polyphenols are an important class of natural antioxidants which act by neutralizing reactive oxygen species (ROS) and chelating transition metal ions. It is postulated that oxidative stress induced by ROS plays an important role in the pathogenesis of many degenerative diseases, including atherosclerosis, diabetes, ischemia, Alzheimer's disease and cancer, as well as the aging process (Halliwell 2008). Additionally, as lipid peroxidation is initiated by ROS, antioxidants retard the oxidative degradation of lipids, and hence, are important components of the nutritional value of food.

This work is a continuation of our research on the chemical composition of polyphenolics in in vitro cultures and plants of the $S$. altissima. The main aim of the study was to perform a comparative analysis of antioxidant potential and content of pharmacologically interesting metabolites (baicalin, wogonoside, luteolin, luteolin-7glucoside and verbascoside) in extracts from in vivoderived plants and in vitro-derived plant materials (shoot cultures and plants) of S. altissima. For the antioxidant activity evaluation, three different in vitro assays were used: scavenging of ABTS (2,2'-azino-bis(3-ethylbenzothiazoline-6-sulphonic acid)) free radicals, metal reduction by FRAP (the ferric reducing antioxidant power) and inhibition of LPO (linoleic acid peroxidation). For quantitative analysis of secondary metabolites, UPLC method was used. To find the connection between antioxidant property of the extracts and their chemical composition, colorimetry was used to determine the total content of phenolic and flavonoid compounds. The useful aspect of the study was to find out whether in vitro systems studied could provide an alternative source of antioxidant constituents.

\section{Materials and methods}

Plant material

For phytochemical analysis, the following types of $S$. altissima plant materials were used:

- shoot culture (passages 6-7, 16-17, 26-27 and 36-37) initiated from the shoot tips of 3-week-old seedlings of S. altissima. The cultures were grown on MS (Murashige and Skoog 1962) agar medium supplemented with $0.1 \mathrm{mg} \mathrm{l}^{-1}$ IAA (indole-3-acetic acid) and $0.45 \mathrm{mg}^{-1}$
BAP (6-benzylaminopurine) and subcultured every 5 weeks on fresh medium. The cultures were kept in a growth chamber at $26 \pm 2{ }^{\circ} \mathrm{C}$ under light conditions $\left(40 \mu \mathrm{M} \mathrm{m}^{-2} \mathrm{~s}^{-1}\right)$ with a photoperiod of $16 \mathrm{~h}$ light and 8 h dark;

- micropropagated plants, named as in vitro-derived plants, harvested either 12 weeks after transfer to the greenhouse or 2 years after transplantation to field conditions (The Medical Plant Garden of the Department of Pharmacognosy, Medical University of Łódź).

Material for the analyses was collected from the aerial parts and roots of these plants. The procedure for plant regeneration was the following: the shoots were multiplied for 5 weeks on MS agar medium with $0.1 \mathrm{mg}^{-1}$ IAA and $0.45 \mathrm{mg}^{-1}$ BAP. They were then transferred individually into small pots containing a sterilized mixture of sand, peat and soil (3:3:4 v/v/v). The plants were rooted ex vitro and grown in the greenhouse for 12 weeks before being transplanted to open field conditions in May 2011. When the plants were harvested the next year, in July 2012, they were about 1 meter tall, highly branched and in the flowering stage.

Plant materials characterized by high levels of secondary metabolites were chosen for the antioxidant, total phenolic and flavonoid content assays: shoot cultures from passage 16-17, as well as the shoots and roots of 2-year-old in vitro-derived plants.

For comparison, the shoots and roots of S. altissima plants derived from seeds provided by the Garden of Medicinal Plants in Wrocław were used for all tests. These in vivo-derived plants, which had also been cultivated for 2 years in the field, demonstrated a morphological similarity to the micropropagated plants of the same age.

\section{Preparation of extracts}

The lyophilized plant material was pre-extracted with chloroform overnight to remove chlorophyll: $250 \mathrm{mg}$ for phytochemical analysis and $1 \mathrm{~g}$ for antioxidant assay. After filtration, the remaining plant material was extracted three times with a 30-ml methanol: water mixture 7:3 (v/v) for $15 \mathrm{~min}$ in ultrasonic bath. The extracts were combined and evaporated under reduced pressure.

\section{UPLC analysis}

The dry residue of extract was dissolved in $2 \mathrm{ml}$ of methanol and subjected to UPLC (ultra-high performance liquid chromatography) analysis. Analysis was performed using an Agilent Technologies 1290 Infinity UPLC apparatus equipped with a diode array detector (DAD) as 
previously described (Grzegorczyk-Karolak et al. 2013). Compounds were identified by comparison of their retention times, UV spectra and mass spectra with those of the standard compounds. The quantification of the following compounds was achieved using calibration curves. Baicalin was purchased from Sigma Aldrich, wogonoside from ChemFace, luteolin and luteolin-7-glucoside from Roth, while verbascoside was provided by Phytoplan. The compound contents were expressed as $\mathrm{mg} \mathrm{g}^{-1}$ of dry weight (wt).

Liquid chromatography-mass spectrometry (LC-MS/MS)

LC-MS/MS was carried out using an API LC/MS/MS system (Applera, USA) with electrospray ionization (ESI) source equipped with Dionex (Germany) HPLC system. The parameters were as described above. Detection was performed in negative ion modes with the conditions set as follows: drying gas $\left(\mathrm{N}_{2}\right) 11.01 \mathrm{~min}^{-1}$, temperature $350{ }^{\circ} \mathrm{C}$, nitrogen nebulizer pressure $40 \mathrm{psi}$, capillary voltage $4.0 \mathrm{~kW}$, a detector gain of $1.600 \mathrm{~V}$, fragmentation voltage $90 \mathrm{~V}$ and full scan range from 100 to $900 \mathrm{~m} / \mathrm{z}$.

Total phenolic determination

Total phenolic content was measured using the FolinCiocalteu method described by Singleton and Rossi (1965). Briefly, $400 \mu \mathrm{l}$ each extract was mixed with $2 \mathrm{ml}$ of Folin-Ciocalteu reagent (POCh, Poland) (diluted 10 -fold) and $1.6 \mathrm{ml}$ of $7.5 \%$ sodium carbonate. The absorbance was determined by spectrophotometry at $765 \mathrm{~nm}$ (Beijing Rayleigh Corp., China) after $30 \mathrm{~min}$ of incubation at room temperature. The results were expressed as gallic acid mg equivalents (GAE) per gram of dry extract. The calibration curve was obtained by preparing a gallic acid solution in the concentration range $1-400 \mathrm{mg} \mathrm{ml}^{-1}$.

\section{Total flavonoid determination}

The flavonoid content was estimated using colorimetric method (Lamaison and Carnat 1990). Briefly, $2 \mathrm{ml}$ of extracts were mixed with $2 \mathrm{ml}$ of $2 \% \mathrm{AlCl}_{3}$. The absorbance of the reaction mixture was measured after $15 \mathrm{~min}$ at room temperature at $415 \mathrm{~nm}$. Quantification was performed with respect to the standard calibration curve of quercetin at a concentration $1-100 \mathrm{mg} \mathrm{ml}^{-1}$. The results were expressed as quercetin mg equivalents (QUE) per gram of dry extract.
Antioxidant assays

\section{ABTS radical scavenging assay}

The antioxidant activity was determined using the ABTS radical cation decolourisation test according to Re et al. (1999). An ABTS stock solution was prepared by $1 \mathrm{ml}$ of $7 \mathrm{mM}$ ABTS (Sigma Aldrich) mixed with $1 \mathrm{ml}$ of $2.45 \mathrm{mM}$ potassium persulfate (Sigma Aldrich). This mixture was kept in the dark at room temperature for 12-16 h before use. ABTS solution was then diluted with methanol to give an absorbance of the negative control $0.7 \pm 0.05$ at $734 \mathrm{~nm}$.

The assays were performed by adding $2 \mathrm{ml}$ of each extract at concentrations of 2.0,20.0, 100.0, 200.0 and $500.0 \mu \mathrm{g} \mathrm{ml}^{-1}$ to $2 \mathrm{ml}$ of ABTS solution. The extent of decolorization associated with ABTS radical chromophore scavenging in the presence of a hydrogen-donating antioxidant was used to estimate the antioxidant properties of the extract. The absorbance was measured after $10 \mathrm{~min}$ at $734 \mathrm{~nm}$. The results were expressed as $\mathrm{EC}_{50}$, the concentration of sample at which $50 \%$ of maximum scavenging activity was recorded, which was calculated from the calibration curve.

\section{FRAP (ferric ion reducing antioxidant power)}

The FRAP was determined according to Pulido et al. (2000) with some modifications. FRAP is a convenient method to estimate the antioxidant capacity of pure compounds and mixtures based on the ferric reducing ability of the extract. At low pH, a Fe ${ }^{3+}$-TPTZ (2,4,6-tris(2-pyridyl)$s$-triazine) complex is reduced to the $\mathrm{Fe}^{2+}$ form with an intense blue color. In this assay, the measurement parameter is defined as the concentration of antioxidant having a $\mathrm{Fe}^{3+}$-TPTZ reducing ability equivalent to that of $1 \mathrm{mM}$ $\mathrm{FeSO}_{4}$. The FRAP assay has advantages over other methods commonly used, because this assay is not dependent on enzymatic or non-enzymatic methods, and the results obtained for the pure compounds are comparable to those observed under physiological conditions (Pulido et al. 2000).

Briefly, $3 \mathrm{ml}$ of fresh prepared FRAP reagent was mixed with $300 \mu \mathrm{l}$ of redistilled water and $100 \mu \mathrm{l}$ of the methanol extract containing the sample. The FRAP reagent contained $2.5 \mathrm{ml}$ of $10 \mathrm{mM}$ TPTZ solution (Sigma Aldrich) in $40 \mathrm{mM} \mathrm{HCl}, 2.5 \mathrm{ml}$ of $20 \mathrm{mM}$ aqueous $\mathrm{FeCl}_{3} \times 6 \mathrm{H}_{2} \mathrm{O}$ solution and $45 \mathrm{ml}$ of $0.3 \mathrm{M}$ acetate buffer at $\mathrm{pH}$ 3.6. The reaction mixture was incubated at $37{ }^{\circ} \mathrm{C}$ for $15 \mathrm{~min}$. The absorbance was measured after $15 \mathrm{~min}$ at $595 \mathrm{~nm}$ relative to a blank sample containing only methanol, not extract. The antioxidant activity was determined against a standard 
of known FRAP value: a calibration curve of $0-2,000 \mu \mathrm{M}$ ferrous sulfate. The results are expressed in $\mu \mathrm{mol} \mathrm{Fe}(\mathrm{II})$ $\mathrm{g}^{-1}$ dry weight of extract.

\section{Linoleic acid peroxidation inhibition}

Linoleic acid peroxidation (LPO) inhibition was determined by the TBARS test according to Choi et al. (2002), with some modifications. The LPO method is a measure of the ability of a sample to inhibit the oxidation of linoleic acid into peroxides.

Briefly, $150 \mu \mathrm{l}$ plant extracts at concentrations of 100 and $250 \mu \mathrm{g} \mathrm{ml}^{-1}$ were mixed with $100 \mu \mathrm{l}$ ascorbic acid $(2 \mathrm{mM}), 500 \mu \mathrm{l}$ linoleic acid $(20 \mathrm{mM})$ and $500 \mu \mathrm{l}$ TRIS$\mathrm{HCl}$ buffer $(100 \mu \mathrm{M}, \mathrm{pH} 7.5)$. Peroxidation was initiated by the addition of $100 \mu \mathrm{l} \mathrm{FeSO}{ }_{4}(4 \mathrm{mM})$. The mixture was incubated for $90 \mathrm{~min}$ at $37{ }^{\circ} \mathrm{C}$. The reaction was terminated by the addition of $1.5 \mathrm{ml}$ ice cold $10 \%$ trichloroacetic acid (TCA) (POCh) in $0.5 \% \mathrm{HCl}$. Following this, $3 \mathrm{ml}$ of 2-thiobarbituric acid (TBA) (Sigma Aldrich) in $50 \mathrm{mM} \mathrm{NaOH}$ was added. The mixture was heated at $95{ }^{\circ} \mathrm{C}$ for $60 \mathrm{~min}$. After cooling, $4 \mathrm{ml}$ of each sample was vortexed with an equal volume of butanol. The mixture was centrifuged for 4,000 rpm for $15 \mathrm{~min}$ and the upper colored layer was decanted into spectrophotometric cuvettes. The absorbance was read at $532 \mathrm{~nm}$. The percentage of linoleic acid peroxidation inhibition was calculated using the following equation:

$$
\begin{aligned}
\% \text { inhibition }= & (\text { Abs control }- \text { Abs sample }- \text { Abs extract }) \\
& \times 100 /(\text { Abs control }- \text { Abs extract })
\end{aligned}
$$

where Abs control is the absorbance of methanol instead of an extract.

\section{Statistical analysis}

The estimated values were calculated as means of six measurements \pm standard error. The significance of the treatment effect was determined using the Kruskal-Wallis test with Statistica 10.0 software (Statsoft Poland). A $5 \%$ probability level was assumed to be significant. MS-Excel software was used to calculate the $\mathrm{EC}_{50}$ and correlation coefficients between the antioxidant assay and the total content of phenolics, as well as those of total flavonoids content, verbascoside, baicalin, wogonoside, luteolin and its 7-O-glucoside.

\section{Results and discussion}

Shoot culture and plant regeneration

The shoot tips of 3-week-old aseptically grown seedlings were used as initial explants for in vitro propagation of
S. altissima plants. On average, over 5 new shoots were formed from one explant on MS agar medium with $0.1 \mathrm{mg} \mathrm{l}^{-1}$ IAA and $0.45 \mathrm{mg} \mathrm{l}^{-1} \mathrm{BAP}$ within 5 weeks. The shoot culture was served as starting material for further multiplication, plant regeneration as well as phytochemical and antioxidant studies. For plant regeneration, the shoots were rooted directly during the transfer to ex vitro conditions. The plants were grown in the greenhouse in pots with mixture of sand, peat and soil $(3: 3: 4 \mathrm{v} / \mathrm{v} / \mathrm{v})$ and after 12 weeks were transferred to field conditions. It was possible to obtain more than 130 plants from one explant in approximately 6 months.

\section{Determination of phenolic compounds}

Methanolic extracts of shoot culture at various ages, the roots and shoots of 12-week-old and 2-year-old micropropagated plants, as well as the roots and shoots of 2-yearold plants propagated from seeds were subjected to UPLC for identification and quantification of phenolic compounds. In all samples, baicalin, wogonoside, luteolin, 7-Oglucoside of luteolin and verbascoside were identified by comparing their retention times $(8.1 \mathrm{~min}, 13.1,12.4,4.0$, 3.6, respectively), UV adsorption profiles and MS data with corresponding standard compounds. LC-MS/MS data of baicalin, wogonoside and verbascoside were presented in our previous work (Grzegorczyk-Karolak et al. 2013). The resulting ion mass spectra of luteolin and its glucoside in the S. altissima extract are shown in Table 1. The comparison of mass spectra with standard compounds and literature data unambiguous identification of luteolin and luteolin-7-glucoside in the studied plant material was conducted (Es-Safi et al. 2005; Fabre et al. 2001).

The highest level of flavonoids characteristic of the Scutellaria genus $\left(22-23 \mathrm{mg} \mathrm{g}^{-1}\right.$ dry wt baicalin and $6.2-6.9 \mathrm{mg} \mathrm{g}^{-1}$ dry wt wogonoside) was found in roots collected from 2-year-old field-grown plants propagated in vitro and from seeds (Table 2). No significant differences were found between roots of both plant types,

Table 1 LC-MS/MS spectrum of luteolin and luteolin-7-glucoside detected in S. altissima extracts

\begin{tabular}{lc}
\hline Compound & MS ions $(\mathrm{m} / \mathrm{z})$ \\
\hline Luteolin & $285.2[\mathrm{M}-\mathrm{H}]^{-} ; 241.2\left[\mathrm{M}-\mathrm{H}-\mathrm{CO}_{2}\right]^{-} ; 175.1[\mathrm{M}-$ \\
& $\left.\mathrm{H}-\mathrm{C}_{3} \mathrm{O}_{2}-\mathrm{C}_{2} \mathrm{H}_{2} \mathrm{O}\right]^{-} ; 199.2\left[\mathrm{M}-\mathrm{H}-\mathrm{C}_{2} \mathrm{H}_{2} \mathrm{O}-\right.$ \\
& $\left.\mathrm{CO}_{2}\right]^{-} ; 243.2\left[\mathrm{M}-\mathrm{H}-\mathrm{C}_{2} \mathrm{H}_{2} \mathrm{O}\right]^{-} ; 217.2[\mathrm{M}-\mathrm{H}-$ \\
& $\left.\mathrm{C}_{3} \mathrm{O}_{2}\right]^{-} ; 174.7\left[\mathrm{M}-\mathrm{H}-\mathrm{catechol}^{-} ; 257.2[\mathrm{M}-\mathrm{H}-\right.$ \\
& $\mathrm{CO}]^{-} ; 213.2\left[\mathrm{M}-\mathrm{H}-\mathrm{CO}_{2}-\mathrm{CO}\right]^{-}$ \\
Luteolin-7-O- & $447.1[\mathrm{M}-\mathrm{H}]^{-} ; 285.1[\mathrm{M}-\mathrm{H}-\mathrm{Glu}]^{-} ; 174.7[\mathrm{M}-\mathrm{H}-$ \\
glucoside & $\mathrm{Glu}-\mathrm{catechol}]^{-} ; 241.1\left[\mathrm{M}-\mathrm{H}-\mathrm{Glu}-\mathrm{CO}_{2}\right]^{-} ; 175.1$ \\
& {$\left[\mathrm{M}-\mathrm{H}-\mathrm{Glu}-\mathrm{C}_{3} \mathrm{O}_{2}-\mathrm{C}_{2} \mathrm{H}_{2} \mathrm{O}\right]^{-} ; 199.2[\mathrm{M}-\mathrm{H}-\mathrm{Glu}-$} \\
& $\left.\mathrm{C}_{2} \mathrm{H}_{2} \mathrm{O}-\mathrm{CO}_{2}\right]^{-} ; 243.2\left[\mathrm{M}-\mathrm{H}-\mathrm{Glu}-\mathrm{C}_{2} \mathrm{H}_{2} \mathrm{O}\right]^{-} ;$ \\
& $217.2\left[\mathrm{M}-\mathrm{H}-\mathrm{Glu}_{-} \mathrm{C}_{3} \mathrm{O}_{2}\right]^{-}$ \\
\hline
\end{tabular}


Table 2 Content of secondary metabolites in S. altissima shoot cultures and plant regenerated in vitro and propagated from seeds

The values are the means of six replicates \pm SE. The means with the same letter in the same column do not differ significantly according to Kruskal-Wallis test $(p \leq 0.05)$

A The shoot cultures grown on MS agar medium supplemented with $0.1 \mathrm{mg}^{-1}$ IAA and $0.45 \mathrm{mg} \mathrm{l}^{-1} \mathrm{BAP}$

B 12-week-old plants grown in pots in the greenhouse

C 2-year-old plants grown in open field conditions

\begin{tabular}{|c|c|c|c|c|c|}
\hline \multirow[t]{2}{*}{ Plant material } & \multicolumn{5}{|c|}{ Contents ( $\mathrm{mg} \mathrm{g}^{-1}$ dry wt) } \\
\hline & Verbascoside & Baicalin & Wogonoside & Luteolin 7-glucoside & Luteolin \\
\hline \multicolumn{6}{|l|}{ Shoot culture ${ }^{\mathrm{A}}$} \\
\hline p. $6-7$ & $4.47 \pm 0.10^{\mathrm{a}}$ & $0.81 \pm 0.05^{\mathrm{a}}$ & $1.06 \pm 0.10^{\mathrm{a}}$ & $0.26 \pm 0.02^{\mathrm{a}}$ & $3.94 \pm 0.11^{\mathrm{a}}$ \\
\hline p. $16-17$ & $4.74 \pm 0.12^{\mathrm{b}}$ & $2.96 \pm 0.13^{\mathrm{b}}$ & $0.87 \pm 0.07^{\mathrm{a}}$ & $0.49 \pm 0.13^{\text {be }}$ & $4.03 \pm 0.30^{\mathrm{ab}}$ \\
\hline p. $26-27$ & $4.05 \pm 0.08^{\mathrm{c}}$ & $2.42 \pm 0.07^{\mathrm{b}}$ & $0.78 \pm 0.05^{\mathrm{a}}$ & $0.44 \pm 0.10^{\mathrm{b}}$ & $3.37 \pm 0.18^{\mathrm{a}}$ \\
\hline p. $36-37$ & $4.26 \pm 0.08^{\mathrm{ac}}$ & $2.54 \pm 0.09^{\mathrm{b}}$ & $0.81 \pm 0.10^{\mathrm{a}}$ & $0.51 \pm 0.08^{\text {be }}$ & $3.29 \pm 0.20^{\mathrm{a}}$ \\
\hline \multicolumn{6}{|c|}{ In vitro-derived plants 12 -week-old ${ }^{\mathrm{B}}$} \\
\hline Shoots & $2.85 \pm 0.12^{\mathrm{d}}$ & $1.71 \pm 0.16^{\mathrm{c}}$ & $0.51 \pm 0.03^{\mathrm{b}}$ & $4.47 \pm 0.48^{\mathrm{c}}$ & $4.52 \pm 0.12^{\mathrm{b}}$ \\
\hline Roots & $0.86 \pm 0.08^{\mathrm{e}}$ & $8.97 \pm 0.54^{\mathrm{d}}$ & $2.46 \pm 0.04^{\mathrm{c}}$ & $0.19 \pm 0.04^{\mathrm{a}}$ & $1.47 \pm 0.21^{\mathrm{c}}$ \\
\hline \multicolumn{6}{|l|}{ 2-year-old ${ }^{C}$} \\
\hline Shoots & $1.74 \pm 0.19^{\mathrm{f}}$ & $0.34 \pm 0.05^{\mathrm{e}}$ & $0.33 \pm 0.07^{\mathrm{b}}$ & $3.14 \pm 0.22^{\mathrm{d}}$ & $2.09 \pm 0.06^{\mathrm{d}}$ \\
\hline Roots & $2.07 \pm 0.02^{\mathrm{d}}$ & $22.15 \pm 0.96^{\mathrm{f}}$ & $6.92 \pm 1.03^{\mathrm{d}}$ & $0.80 \pm 0.01^{\mathrm{e}}$ & $0.81 \pm 0.01^{\mathrm{e}}$ \\
\hline \multicolumn{6}{|c|}{ In vivo-derived plants 2 -year-old ${ }^{C}$} \\
\hline Shoots & $1.38 \pm 0.09^{\mathrm{f}}$ & $0.27 \pm 0.05^{\mathrm{e}}$ & $0.31 \pm 0.04^{\mathrm{b}}$ & $2.33 \pm 0.41^{\mathrm{d}}$ & $2.05 \pm 0.02^{\mathrm{d}}$ \\
\hline Roots & $2.03 \pm 0.21^{\mathrm{d}}$ & $22.57 \pm 1.41^{\mathrm{f}}$ & $6.21 \pm 0.56^{\mathrm{d}}$ & $0.87 \pm 0.08^{\mathrm{e}}$ & $0.57 \pm 0.05^{\mathrm{e}}$ \\
\hline
\end{tabular}

derived in vitro and in vivo, with regard to the content of other metabolites: verbascoside, luteolin, or luteolin-7glucoside. Similar levels of polyphenolic compounds including baicalin and wogonoside indicate metabolic similarities between plants regenerated in vitro and those propagated from seeds. On the other hand, the results in Table 2 showed that the yield of secondary metabolites in $S$. altissima plants was strongly influenced by age. The content of baicalin and wogonoside in the roots of 12-week-old greenhouse-grown micropropagated plants was 2.5-3 times lower than those of the roots of fieldgrown plants, regardless of whether they had been propagated in vitro or in vivo. In contrast, twice as much luteolin was found in the in vitro material (Table 2).

The comparative analysis of flavonoids in the roots and aerial parts of $S$. altissima plants showed that root extract contains markedly higher amounts of baicalin and wogonoside. For example, the amount of baicalin in shoot extracts obtained from field-grown plants ranged from $0.27 \mathrm{mg} \mathrm{g}^{-1}$ dry $\mathrm{wt}$, in plants grown from seeds, to $0.34 \mathrm{mg} \mathrm{g}^{-1}$ dry wt, in micropropagated plants, and these values were 65-80 times lower than in the corresponding root extracts. A similar tendency was observed in younger tissue culture-derived plants ( 12 weeks old), but the differences between the levels of baicalin and wogonoside in roots and shoots were smaller: 8.97 vs. $1.71 \mathrm{mg} \mathrm{g}^{-1}$ dry wt and 2.46 vs. $0.51 \mathrm{mg} \mathrm{g}^{-1}$ dry wt, in roots and shoots, respectively. Also, in the other Scutellaria species (S. baicalensis, S. tomentosa and S. wrightii) baicalin and wogonoside levels were higher in roots than in stems and leaves (Islam et al. 2011). It may be due to the translocation of flavonoids (baicalin and wogonoside) in rooted shoots from leaves to roots. It is known that flavonoids are biosynthesized in leaves in many plant species, because the expression of its biosynthesis pathway genes is strictly dependent on light (Petrussa et al. 2013). A literature review revealed no previous data on the quantitative analysis of wogonoside and verbascoside in S. altissima. While only one report on the occurrence of baicalin in the plant species has been published (Zgórka 2006). In the report, Zgórka described that the level of baicalin in the aerial parts of S. altissima reached $0.3 \mathrm{mg} \mathrm{g}^{-1}$ dry wt, which is consistent with our results. She has not estimated the content of the flavone in the roots of the plant.

The content of baicalin, wogonoside, verbascoside or luteolin and its glycoside in S. altissima shoot culture were also measured by UPLC. Accumulation of baicalin and wogonoside was found to be higher in the shoots grown on MS medium supplemented with $0.1 \mathrm{mg} \mathrm{l}^{-1}$ IAA and $0.45 \mathrm{mg}^{-1}$ BAP than in the sample taken from the shoots of 12-week-old greenhouse-grown micropropagated plants and from the shoots of field-grown plants, although this accumulation was significantly lower than that seen in the plant roots. These differences can be probably due to in vitro conditions, such as basal medium composition and growth regulators utilized to establish cultures. It has been reported that the type and concentration of growth regulators are often crucial factors in secondary metabolite accumulation in organ culture (Al-Qudah et al. 2011).

The influence of the age of $S$. altissima multiple shoot culture on the level of secondary metabolites showed that the culture retained the ability to biosynthesize analyzed compounds during long-term cultivation of 3.5 years. The highest amounts of the secondary metabolites were obtained from shoots after 1.5 years of growth under in vitro conditions, 16-17th subcultures, and these levels 
remained more or less stable in subsequent passages: 26-27th and 36-37th subcultures (Table 2).

Antioxidant activity and total phenolic and flavonoid contents

The antioxidative capacities of methanolic extracts of shoots cultured in vitro (passages 16-17), micropropagated shoots and roots and seed-derived plants grown in the field were determined. To fully characterize their antioxidant properties, three in vitro tests based on different mechanisms were used in the study. The free radical scavenging activity of the tested extracts was evaluated by the ABTS assay. The FRAP assay was employed to measure the ability to reduce iron ions $\left(\mathrm{Fe}^{3+}\right.$ to $\left.\mathrm{Fe}^{2+}\right)$. Both tests are based on the mechanism of single electron transfer, i.e., the SET (single electron transfer) reaction. Linoleic acid peroxidation was used to determine the ability of S. altissima extracts to inhibit the oxidation of linoleic acid into peroxides via the HAT (hydrogen atom transfer) mechanism, which involves the reduction of free radicals through the transfer of hydrogen from the molecule of antioxidant. This assay is more physiopathologically important for screening antioxidant activity in human body than other methods (Matkowski 2006). Additionally, total phenolic and flavonoid contents in the extracts were evaluated by colorimetric methods.

All tested extracts showed ABTS radical scavenging ability with $\mathrm{EC}_{50}$ values in the range of 30-50 micrograms per milliliter (Table 3). The highest activity in the test, with $99 \%$ radical inhibition at a concentration of $100 \mu \mathrm{g} \mathrm{ml}^{-1}$ and $\mathrm{EC}_{50}$ value about $30 \mu \mathrm{g} \mathrm{ml}^{-1}$ was demonstrated by extracts from the roots and shoots of regenerated plants. The activity was similar to that observed in

Table 3 Antioxidant activities of S. altissima extracts determined by the ABTS scavenging assay and reducing power (FRAP)

\begin{tabular}{lcc}
\hline Plant material & \multicolumn{1}{c}{ FRAP assay $^{\mathrm{A}}$} & ABTS assay $^{\mathrm{B}}$ \\
\hline Shoot culture & $253.91 \pm 0.55^{\mathrm{a}}$ & $48.8 \pm 6.75^{\mathrm{a}}$ \\
In vitro-regenerated plants & \\
$\quad$ Shoots & $399.12 \pm 8.32^{\mathrm{b}}$ & $30.11 \pm 0.47^{\mathrm{b}}$ \\
Roots & $502.85 \pm 11.16^{\mathrm{c}}$ & $30.19 \pm 0.17^{\mathrm{b}}$ \\
In vivo plants & $391.66 \pm 6.13^{\mathrm{b}}$ & $39.72 \pm 0.64^{\mathrm{c}}$ \\
Shoots & $367.37 \pm 7.23^{\mathrm{b}}$ & $34.12 \pm 4.0^{\mathrm{b}}$ \\
Roots &
\end{tabular}

The means with the same letter do not differ significantly according to the Kruskal-Wallis test $(p \leq 0.05)$. The values are means of six replicates \pm SE

A Ferric reducing antioxidant power expressed in $\mu$ mol Fe(II) $g^{-1}$ dry wt, 15 min of incubation

в $\mathrm{EC}_{50}$ the concentration of sample $\left[\mu \mathrm{g} \mathrm{ml}^{-1}\right]$ showing $50 \%$ of maximal radical scavenging activity the root extracts of conventionally propagated S. altissima $\left(34.12 \mu \mathrm{g} \mathrm{ml}^{-1}\right)$. The shoot extracts of in vivo-derived plants had a lower ability to scavenge free radicals $\left(E_{50}=39.7 \mu \mathrm{g} \mathrm{ml}^{-1}\right)$. The lowest antiradical activity was demonstrated by shoot culture extract $\left(\mathrm{EC}_{50}=50\right.$ $\mu \mathrm{g} \mathrm{ml}^{-1}$ ) (Table 3).

Similar to the ABTS assay, the best reducing ability according to the FRAP test was observed for the root extract of regenerated plants $\left(503 \mu \mathrm{mol} \mathrm{Fe}(\mathrm{II}) \mathrm{g}^{-1}\right.$ dry wt), which was significantly higher than those of the shoot extracts of in vitro propagated plants $\left(400 \mu \mathrm{mol} \mathrm{Fe}(\mathrm{II}) \mathrm{g}^{-1}\right.$ dry wt) and both shoot and root extracts of in vivo-derived plants, with a reducing capacity ranging from 370 to $400 \mu \mathrm{mol} \mathrm{Fe}(\mathrm{II}) \mathrm{g}^{-1}$ dry wt. The FRAP values for $S$. altissima plants were comparable to or better than those reported by Henriquez et al. (2011) for berry fruits such as blackberries (344.1 $\mu \mathrm{M} \mathrm{Fe}^{2+} \mathrm{g}^{-1}$ dry wt), blueberries $\left(257.4 \mu \mathrm{M} \mathrm{Fe}^{2+} \mathrm{g}^{-1}\right.$ dry wt), raspberries $\left(229.6 \mu \mathrm{M} \mathrm{Fe}^{2+}\right.$ $\mathrm{g}^{-1}$ dry wt) and strawberries $\left(303 \mu \mathrm{M} \mathrm{Fe}^{2+} \mathrm{g}^{-1}\right.$ dry wt), known for their antioxidant properties. The least reducing ability was observed in shoot extracts from $S$. altissima cultured under in vitro conditions (about $250 \mu \mathrm{M} \mathrm{Fe}^{2+} \mathrm{g}^{-1}$ dry wt).

The inhibition of linoleic acid peroxidation (LPO) by $S$. altissima extracts was assayed by the TBARS test, and the results are presented in Fig. 1. The extracts exhibited a dose-dependent inhibition potential, which ranged between 15 and $30 \%$ at a concentration of $100 \mu \mathrm{g} \mathrm{ml}^{-1}$, and between 30 and $50 \%$ at a concentration of $250 \mu \mathrm{g} \mathrm{ml}^{-1}$. The root extracts of regenerated plants exhibited the highest LA inhibition (30\%), while the roots of plants derived from seeds showed significantly weaker activity, with an inhibitory effect of $26 \%$ at a concentration of

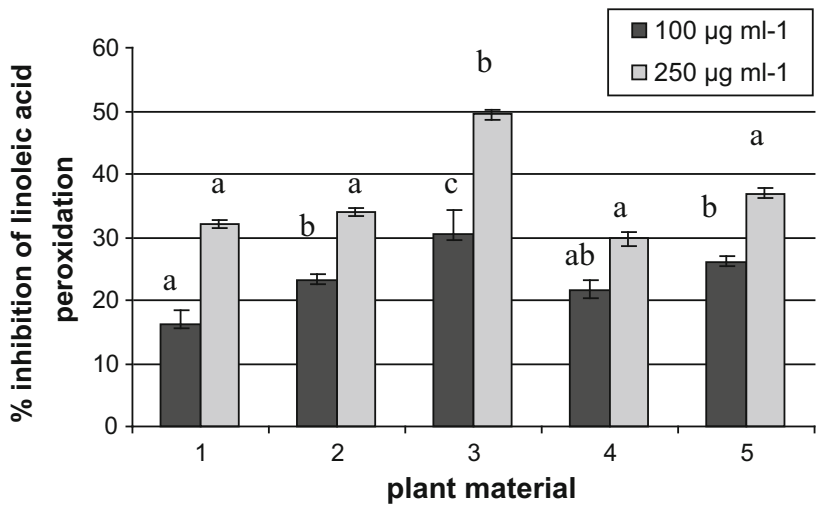

Fig. 1 Inhibition of linoleic acid peroxidation by $S$. altissima methanolic extracts at the concentration of 100 and $250 \mu \mathrm{g} \mathrm{ml}^{-1}$ in the Fe/ascorbic acid system using TBARS detection. 1 shoot culture, 2 shoots in vitro-regenerated plants, 3 roots in vitro-regenerated plants, 4 shoots in vivo-derived plants, 5 roots in vivo-derived plants. The means with the same letter for the same extract concentration do not differ significantly according to the Kruskal-Wallis test $(p \leq 0.05)$. The values are the means of three replicates $\pm \mathrm{SE}$ 
$100 \mu \mathrm{g} \mathrm{ml}^{-1}$. The results of our study suggest that the antioxidant mechanism of the compounds present in $S$. altissima is rather based on the single electron transfer reaction than on hydrogen atom reaction. The obtained values suggest that the lipid peroxidation inhibiting activity of $S$. altissima extracts was weaker than known antioxidant compounds such as BHT: $78 \%$ inhibition at $100 \mu \mathrm{g} \mathrm{ml}^{-1}$ (data not published). However, the widely used synthetic compound has been recently restricted because of serious concerns about its carcinogenic potential (Buxiang and Fukuhara 1997).

It had been reported that antioxidant activity can be associated with the content of phenolic compounds, especially flavonoids, in plant material (Tundis et al. 2013; Gao et al. 1999). Therefore, in this study, the total phenolic and flavonoid contents of $S$. altissima extracts were evaluated. In all assays used in our experiments (ABTS, FRAP, LPO), the highest antioxidant properties were demonstrated by extracts from the roots of in vitro-regenerated plants, which were also characterized by the highest total phenolic and flavonoid content: $45.2 \mathrm{mg}$ GAE per g of extract dry wt and $24.6 \mathrm{mg}$ QUE per $\mathrm{g}$ of extract dry wt, respectively. The shoot extracts of the plants contained similar total content of phenolic compounds as extracts of roots, $42.8 \mathrm{mg}$ GAE per $g$ of extract dry wt compared to $45.2 \mathrm{mg}$ GAE per $\mathrm{g}$ of extract dry wt, respectively, but the total flavonoid amount in the former was lower: $15.5 \mathrm{mg}$ QUE per $\mathrm{g}$ of extract dry wt vs. $24.6 \mathrm{mg}$ QUE per g of extract dry wt. Significantly, lower total phenolic and flavonoid content was recorded from the extracts of shoots and roots of in vivo-derived plants, whereas the lowest contents were detected in the extract from S. altissima in vitro shoot culture (Table 4).

Table 5 shows the values of correlation coefficients calculated for antioxidant assay versus total phenolic and flavonoid contents, as well as the contents of main phenolic compounds, identified by UPLC, in extracts of S. altissima., i.e., baicalin, wogonoside and verbascoside. The data

Table 4 The content of phenolic and flavonoid compounds in $S$. altissima extracts

\begin{tabular}{lll}
\hline Plant material & $\begin{array}{l}\text { Total phenolic content } \\
\mathrm{mg} \mathrm{GAE} \mathrm{g}^{-1} \text { dry wt }\end{array}$ & $\begin{array}{l}\text { Total flavonoid content } \\
\mathrm{mg} \mathrm{QUE} \mathrm{g}^{-1} \text { dry wt }\end{array}$ \\
\hline Shoot culture & $\begin{array}{c}21.41 \pm 0.25^{\mathrm{a}} \\
\text { In vitro-regenerated plants }\end{array}$ & $8.75 \pm 0.05^{\mathrm{a}}$ \\
$\quad$ Shoots & $42.83 \pm 0.52^{\mathrm{b}}$ & $15.5 \pm 0.14^{\mathrm{b}}$ \\
$\quad$ Roots & $45.18 \pm 0.44^{\mathrm{b}}$ & $24.6 \pm 0.03^{\mathrm{c}}$ \\
In vivo plants & & \\
$\quad$ Shoots & $30.52 \pm 0.09^{\mathrm{c}}$ & $14.01 \pm 0.15^{\mathrm{b}}$ \\
Roots & $30.51 \pm 0.32^{\mathrm{c}}$ & $13.83 \pm 0.13^{\mathrm{b}}$ \\
\hline
\end{tabular}

The values are the means of six replicates \pm SE. The means with the same letter in the same column do not differ significantly according to the Kruskal-Wallis test $(p \leq 0.05)$
Table 5 Correlation coefficients between the antioxidant activity of S. altissima extracts and total content of phenolic and flavonoid compounds and baicalin, wogonoside and verbascoside content

\begin{tabular}{lccc}
\hline & ABTS & FRAP & LPO \\
\hline Total phenolics & $\mathbf{0 . 9 2 9}$ & $\mathbf{0 . 8 9 7}$ & 0.639 \\
Total flavonoids & 0.766 & $\mathbf{0 . 9 6 2}$ & 0.738 \\
Baicalin & 0.446 & 0.466 & 0.322 \\
Wogonoside & 0.480 & 0.529 & 0.394 \\
Verbascoside & -0.690 & -0.745 & 0.107 \\
\hline
\end{tabular}

Bold values indicate very strong correlation

suggest that both radical scavenging ability and reducing power of the analyzed extracts were strongly correlated with total content of phenolic compounds $(r=0.93$ and 0.90 , respectively) and less with baicalin ( $r=0.46,0.47)$ and wogonoside $(r=0.48,0.53)$ content. The results in Table 5 indicate that the total phenolic content measured by the Folin-Ciocalteu method is a more informative parameter for contributing to the antioxidant activity of S. altissima extracts than concentrations of the individual flavonoids detected in the extracts. A remarkable example is the shoot extract taken from in vitro-regenerated plants of $S$. altissima. Its antioxidant activity in ABTS assay was comparable to that revealed for the root extract of micropropagated plants. Both extracts have similar total content of phenolic compounds. However, as shown by UPLC analysis, the extract from the aerial parts had much lower concentrations of baicalin and wogonoside as compared to the extract from the underground parts of regenerated plants (Table 2). The same tendency was observed when extracts from the roots and shoots of seed-derived plants of S. altissima were compared (Tables 2, 4). It is known that the antioxidant activity of flavonoids is strongly structurally dependent (Pulido et al. 2000). Various authors report that the antioxidant ability of flavonoids increases under the following conditions: (1) the presence of a $3^{\prime} 4^{\prime}$-dihydroxy structure in B ring, (2) the presence of 2,3-double bond in conjunction with the 4-oxo group in the heterocycle allowing for conjugation between the $\mathrm{A}$ and $\mathrm{B}$ rings and (3) the presence of 3- and 5-hydroxyl groups in the A ring together with a 4-oxo function in the $\mathrm{A}$ and $\mathrm{C}$ rings (Pulido et al. 2000; Rice-Evans et al. 1996). Baicalin does not meet the first condition; therefore, it is less effective in reacting with the most reactive oxygen species than for example quercetin or luteolin (Gao et al. 1999). The latter flavone was detected in shoot extracts of both in vitro- and in vivo-derived plants of S. altissima in considerably higher amounts than in root extracts (Table 2). The lower correlation between total phenolic compounds and flavonoids content and LPO assay suggests that these compounds play a minor role as determinants of the lipid peroxidation inhibiting activity. 
Correlation analysis also indicates that verbascoside content did not show correlation with performed assays. Conversely, Si et al. (2013), report a strong relationship between verbascoside content and antioxidant activity of Paulownia tomentosa bark extracts. It is possible that in $S$. altissima extracts, verbascoside occurred at a concentration (0.9-4.75 mg g-1 dry wt) which was too low to have any significant effect on the antioxidant properties of analyzed plant materials.

\section{Conclusion}

To our knowledge, all results on S. altissima shoot culture and plants derived from shoots rooted ex vitro are presented here for the first time. The most important finding is that in vitro- and in vivo-propagated plants of the same age, i.e., 2-year-old plants grown in the field contained similar levels of the pharmacologically active flavones, baicalin and wogonoside. Hence, the roots of in vitro-raised $S$. altissima plants can be considered as alternative sources of these compounds.

The results of the study show also that the methanolic extracts of roots of micropropagated plants displayed interesting antioxidant capacities comparable to the root extract of conventionally propagated plants, according to the ABTS assay, or even higher, according to the FRAP and LPO assays. The correlation analysis revealed that the results of all three tests correlated the best with the total phenolic levels estimated by Folin-Ciocalteu method. These results, as well as high total content of phenolic and flavonoid compounds known to be present in the extracts of shoots and roots of micropropagated plants, indicate that further study on the identification of other phenolic compounds unidentified in this study, and the establishment of their significance in the antioxidant potential of S. altissima plants is necessary.

Author contribution statement I. Grzegorczyk-Karolak obtained shoot cultures, regenerated plants, performed antioxidant assays and described the results. Ł. Kuźma performed UPLC analysis. H. Wysokinska was responsible for verification of the paper.

Open Access This article is distributed under the terms of the Creative Commons Attribution License which permits any use, distribution, and reproduction in any medium, provided the original author(s) and the source are credited.

\section{References}

Al-Qudah TS, Shibli RA, Alali FQ (2011) In vitro propagation and secondary metabolites production in wild germander (Teucrium polium L.). In Vitro Cell Dev Biol Plant 47:496-505. doi:10. 1007/s11627-011-9352-9
Beshko NP, Gella EV, Litvinenko VI, Kovalev IP, Gordienko VG (1975) Flavonoids of the roots of Scutellaria altissima. Chem Nat Compd 11:533-534. doi:10.1007/BF00566807

Buxiang S, Fukuhara M (1997) Effects of coadministration of butylated hydroxytoluene, butylated hydroxyanisole and flavonoid on the activation of mutagens and drug-metabolizing enzymes in mice. Toxicology 122:61-72. doi:10.1016/S0300483X(97)00078-4

Chang WH, Chem CH, Lu FJ (2002) Different effects of baicalein, baicalin and wogonin on mitochondrial function, glutathione content and cell cycle progression in human hepatoma cell lines. Planta Med 68:128-132. doi:10.1055/s-2002-20246

Chen Y, Lu N, Ling Y, Gao Y, Wang L, Sun Y, Qi Q, Feng F, Liu W, You Q, Gao Q (2009) Wogonoside inhibits lipopolysaccharideinduced angiogenesis in vitro and in vivo via toll-like receptor 4 signal transduction. Toxicology 259:10-17. doi:10.1016/j.tox. 2009.01.010

Choi CW, Kim SC, Hwang SS, Choi BK, Ahn HJ, Lee MY, Park SH, Kim SK (2002) Antioxidant activity and free radical scavenging capacity between Korean medicinal plants and flavonoids by assay_guided comparison. Plant Sci 163:1161-1168. doi:10. 1016/S0168-9452(02)00332-1

Cole IB, Cao J, Alan AR, Saxena PK, Murch SJ (2008) Comparisons of Scutellaria baicalensis, Scutellaria lateriflora and Scutellaria racemosa: genome size, antioxidant potential and phytochemistry. Planta Med 74:474-481. doi:10.1055/s-2008-1034358

Es-Safi NE, Kerhoas L, Einhorn J, Ducrot PH (2005) Application of ESI/MS, CID/MS and tandem MS/MS to the fragmentation study of eriodictyol 7-O-glucosyl-( $1 \rightarrow 2)$-glucoside and luteolin 7-O-glucosyl- $(1 \rightarrow 2)$-glucoside. Int $\mathrm{J}$ Mass Spectrom 247:93-100. doi:10.1016/j.ijms.2005.10.002

Fabre N, Rustan I, de Hoffmann E, Quetin-Leclercq J (2001) Determination of flavone, flavonol, and flavanone aglycones by negative ion liquid chromatography electrospray ion trap mass spectrometry. J Am Soc Mass Spectrom 12:707-715. doi:10. 1016/S1044-0305(01)00226-4

Gao Z, Huang K, Yang X, Xu H (1999) Free radical scavenging and antioxidant activities of flavonoids extracted from the radix of Scutellaria baicalensis Georgi. Biochim Biophys Acta 1472:643-650. doi:10.1016/S0304-4165(99)00152-X

Grzegorczyk-Karolak I, Kuźma Ł, Wysokińska H (2013) The use of long-term Scutellaria altissima callus cultures for shoot regeneration, production of bioactive metabolites and micropropagation. J Med Plants Res 7:3003-3313. doi:10.5897/JMPR2013. 5226

Halliwell B (2008) Are polyphenols antioxidants or pro-oxidants? What do we learn from cell culture and in vivo studies? Arch Biochem Biophys 476:107-112. doi:10.1016/j.abb.2008.01.028

Henriquez C, Lopez-Alarcon C, Gomez M, Lutz M, Speisky H (2011) Time-dependence of ferric reducing antioxidant power (FRAP) index in Chilean apples and berries. Arch Latinoam Nutr 61:323-332

Islam MN, Downey F, Ng CKY (2011) Comparative analysis of bioactive phytochemicals from Scutellaria baicalensis, Scutellaria lateriflora, Scutellaria racemosa, Scutellaria tomentosa and Scutellaria wrightii by LC-DAD-MS. Metabolomics 7:446-453. doi:10.1007/s11306-010-0269-9

Kitamura K, Honda M, Yoshizaki H, Yamamoto S, Nakane H, Fukushima M, Ono K, Tokunaga T (1998) Baicalin, an inhibitor of HIV-1 production in vitro. Antivir Res 37:131-140. doi:10. 1016/S0166-3542(97)00069-7

Lamaison JL, Carnat A (1990) Content of principal flavonoids of the flowers and leaves of Crataegus monogyna Jacq. and Crataegus laevigata (Poiret) DC. (Rosaceae). Pharm Acta Helv 65:315-320

Lim BO (2003) Effects of wogonin, wogonoside, and 3,5,7,2',6' pentahydroxyflavone on chemical mediator production in 
peritoneal exduate cells and immunoglobulin $\mathrm{E}$ of rat mesenteric lymph node lymphocytes. J Ethnopharmacol 84:23-29. doi:10. 1016/S0378-8741(02)00257-X

Matkowski A (2006) Plant phenolic metabolites as antioxidants and antimutagenesis inhibitors. In: Blume Y, Smertenko P, Durzan DJ (eds) NATO life science monographs, vol 376. IOS Press, Amsterdam, pp 129-148

Murashige T, Skoog F (1962) A revised medium for rapid growth and bioassays with tobacco tissue cultures. Physiol Plant 15:472-497

Pan J, Yuan CS, Lin CJ, Jia ZJ, Zheng RL (2003) Pharmacological activities and mechanisms of natural phenylpropanoid glycosides. Pharmazie 58:767-775. doi:10.1002/chin.200405273

Petrussa E, Braidot E, Zancani M, Peresson C, Bertolini A, Patui S, Vianelli A (2013) Plant flavonoid-biosynthesis, transport and involvement in stress responses. Int J Mol Sci 14:14950-14973. doi:10.3390/ijms 140714950

Pulido R, Bravo L, Saura-Calixto F (2000) Antioxidant activities of dietary phenols are determined by a modified ferric reducing/ antioxidant power assay. J Agric Food Chem 48:3396-3402. doi:10.1021/jf9913458

Re R, Pellegrini N, Proteggente A, Pannala A, Yang M, Rice-Evans C (1999) Antioxidant activity applying an improved ABTS radical cation decolorizing assay. Free Radic Biol Med 26:1231-1237. doi:10.1016/S0891-5849(98)00315-3

Rice-Evans CA, Miller NJ, Paganga G (1996) Structure-antioxidant activity relationships of flavonoids and phenolic acids. Free
Radic Biol Med 20:933-956. doi:10.1016/0891-5849(95)022279

Shang XF, He XR, He XY, Li MX, Zhang RX, Fan PC, Zhang QL, Jia ZP (2010) The genus Scutellaria an ethnopharmacological and phytochemical review. J Ethnopharmacol 128:279-313. doi:10.1016/j.jep.2010.01.006

Si CL, Liu SC, Hu HY, Jiang JZ, Yu GJ, Ren XD, Xu GH (2013) Activity-guided screening of the antioxidants from Paulownia tomentosa var. tomentosa bark. BioResources 8:628-637

Singleton VL, Rossi JA (1965) Colorimetry of total phenolics with phosphomolybdic-phosphotungstic acid reagents. Am J Enol Vitic 16:144-153

Tundis R, Nadjafi F, Menichini F (2013) Angiotensin-converting enzyme inhibitory activity and antioxidant properties of Nepeta crassifolia Boiss \& Buhse and Nepeta binaludensis Jamzad. Phytother Res 27:572-580. doi:10.1002/ptr.4757

Wiczańska-Barska A, Królicka A, Głód D, Majdan M, Kawiak A, Krauze-Baranowska M (2012) Enhanced accumulation of secondary metabolites in hairy root cultures of Scutellaria lateriflora following elicitation. Biotechnol Lett 34:1757-1763. doi:10. 1007/s10529-012-0963-y

Zgórka G (2006) Retention behavior of silica-bonded and novel polymeric reversed-phase sorbents in studies on flavones as chemotaxonomic markers of Scutellaria L. genus. J Chromatogr A 1120:230-236. doi:10.1016/j.chroma.2005.11.109 